Article

\title{
Culturing-Enriched Metabarcoding Analysis of the Oryctes rhinoceros Gut Microbiome
}

\author{
Matan Shelomi ${ }^{1, *(1)}$ and Ming-Ju Chen ${ }^{2}$ (1) \\ 1 Department of Entomology, National Taiwan University; Taipei City 10617, Taiwan \\ 2 Department of Animal Science and Technology, National Taiwan University, Taipei City 10673, Taiwan; \\ cmj@ntu.edu.tw \\ * Correspondence: mshelomi@ntu.edu.tw; Tel.: +886-02-3366-5588
}

Received: 16 October 2020; Accepted: 9 November 2020; Published: 11 November 2020

Simple Summary: The coconut rhinoceros beetle is a pest of palm trees, which may have symbiotic gut microbes that help it digest its food. These microbes may produce enzymes like cellulase, which have uses in human industry. If the microbes are essential for the beetle's survival, then finding ways to attack the microbes could help fight the pest. We sampled microbes from the guts of larval beetles collected in coconut trees in southern Taiwan, and identified the microbes both by culturing and with molecular biology methods. We found several species of bacteria and a yeast, Candida xylanolytica, with potential digestive functions for the beetle. Some of these microbes had been reported in these beetles before while others are new. Broader surveys of the beetle microbiome are needed to determine whether or not they have a conserved microbiome.

\begin{abstract}
Wood-feeding insects should have a source of enzymes like cellulases to digest their food. These enzymes can be produced by the insect, or by microbes living in the wood and/or inside the insect gut. The coconut rhinoceros beetle, Oryctes rhinoceros, is a pest whose digestive microbes are of considerable interest. This study describes the compartments of the O. rhinoceros gut and compares their microbiomes using culturing-enriched metabarcoding. Beetle larvae were collected from a coconut grove in southern Taiwan. Gut contents from the midgut and hindgut were plated on nutrient agar and selective carboxymethylcellulose agar plates. DNA was extracted from gut and fat body samples and 16S rDNA metabarcoding performed to identify unculturable bacteria. Cellulase activity tests were performed on gut fluids and microbe isolates. The midgut and hindgut both showed cellulolytic activity. Bacillus cereus, Citrobacter koseri, and the cellulolytic fungus Candida xylanilytica were cultured from both gut sections in most larvae. Metabarcoding did not find Bacillus cereus, and found that either Citrobacter koseri or Paracoccus sp. were the dominant gut microbes in any given larva. No significant differences were found between midgut and hindgut microbiomes. Bacillus cereus and Citrobacter koseri are common animal gut microbes frequently found in Oryctes rhinoceros studies while Candida xylanilytica and the uncultured Paracoccus sp. had not been identified in this insect before. Some or all of these may well have digestive functions for the beetle, and are most likely acquired from the diet, meaning they may be transient commensalists rather than obligate mutualists. Broader collection efforts and tests with antibiotics will resolve ambiguities in the beetle-microbe interactions.
\end{abstract}

Keywords: cellulase; rhinoceros beetles; digestive system; symbiosis; microbiome

\section{Introduction}

Animals that feed on wood frequently depend on plant cell wall-degrading enzymes, such as cellulase and xylanase, to degrade their recalcitrant diet into digestible sugars. These enzymes can be 
produced by the animal endogenously, or by microbes living in the wood or in close external or internal symbioses with the host [1]. These two options are not mutually exclusive, as in the case of termites, where the insect and their gut microbes produce a cocktail of enzymes to fully digest wood into sugar monomers [2]. Interest in the digestive enzymes and microbial symbionts of wood-eating insects is growing due to demand for these enzymes in industries, such as bioconversion [3,4], on top of the basic science interests in how these systems differ across Insecta and how wood feeding convergently evolved in different groups $[5,6]$.

The coconut rhinoceros beetle, Oryctes rhinoceros (Coleoptera: Scarabaeidae), is a widespread tropical pest of palm trees from India through the South Pacific [7]. The adults bore into and feed on the crown meristem, destroying the growing points, reducing yields, and stunting or killing the tree. They are pests of economically important species, such as coconut (Cocos nucifera), rattan (Calamus sp.), raffia (Raphia ruffia), areca nut (Areca catechu), oil palm (Elaeis sp.), pandan (Pandanus sp.), salak (Salacca zalacca), sago (Metroxylon sagu), date (Phoenix dactylifera), and ornamental palms (e.g., Roystonea regia, Livistona chinensis, Corypha umbraculifer). They are also known to feed on non-palms, such as banana, taro, sugar cane, papaya, sugar apple, and pineapple [8,9]. While the adults are the destructive stage, the larvae feed on rotting wood from dead or fallen trunks. This wood is high in plant cell wall polysaccharides, requiring enzymes to break down, but also should be rich in cellulolytic microbes naturally found in decaying wood. As the larvae and adults do not interact, any symbiotic microbes the larvae need for digestion, if they exist, would either be passed down vertically and be housed in tissues, such as mycetocytes in the gut or fat body, or be acquired from the diet/environment. Analysis of the gut microbiome of such beetle larvae would reveal both transient microbes passing through the gut with the food and also symbionts, obligate or facultative, that reside in the gut longer than the transit time needed for food to pass or which replicate and develop in the gut to reach higher densities than in the substrate [6].

Several researchers have tried to characterize the microbiome of Oryctes rhinoceros, producing important findings like the pathogenic Oryctes rhinoceros nudivirus used in managing this pest [10] and the discovery of antimicrobial peptides such as rhinocerosin [11] and scarabaecin [12]. These efforts typically focused on bacteria and used either culturing or culturing-independent methods, such as metabarcoding and denatured gradient gel electrophoresis of the 16S rRNA genes to identify and quantify the microbial community in the guts, with only one study so far attempting both [13]. The results vary, with beetles in different locations having different microbes, and studies on other species of Oryctes showing different microbiomes yet [14,15]. Efforts to culture microbes expressing plant cell wall-degrading enzymes in particular have been successful but inconsistent. Cellulolytic Bacillus brevis was isolated from the beetles in Nigeria [16]; cellulolytic, xylanolytic, and mannolytic Citrobacter koseri, Bacillus pumilus, Bacillus subtilis, Bacillus cereus, and Bacillus aryabhattai were isolated in Java, Indonesia [17]; and cellulolytic Citrobacter sp. and lignolytic Bacillus sp. were isolated in Sumatra, Indonesia [18]. Species of Citrobacter and Bacillus are almost always found in Oryctes rhinoceros studies, though they are not always checked for enzymatic activity [13,19].

The goals of this experiment were to produce an in-depth look at the gut microbiome of Oryctes rhinoceros from a single location through a physiological context. This project sought to compare the microbiome in the larval midgut and hindgut with both culturing and culture-independent analysis, to look for microbial cellulases, and to describe the gut anatomy, which has not yet been done. This work thus provides a novel look at how gut physiology, enzymatic digestion, and microbiota interact in this pest beetle.

\section{Materials and Methods}

\subsection{Insect Source}

Larval Oryctes rhinoceros were collected from a single coconut (Cocos nucifera) grove on October 2019 in Tianyu village, Wandan Township, Pingtung County, Taiwan $\left(22^{\circ} 35^{\prime} 05.4^{\prime \prime} \mathrm{N}, 120^{\circ} 28^{\prime} 22.8^{\prime \prime} \mathrm{E}\right)$. 
No approval was needed to collect or study these pest insects. O. rhinoceros is the only known Oryctes species in Taiwan, and larvae were identified as Oryctes using a key [20]. Insects and coconut pulp were collected in large plastic bins and transported to the Entomology Museum of National Taiwan University. Larvae survived entirely on the coconut palm they were transported with, and were maintained in the bins for up to two weeks until dissection. Larvae were between 50 and $70 \mathrm{~mm}$ in length at the time of dissection. Several larvae were maintained until adulthood, and were confirmed with keys and museum specimens to also be O. rhinoceros.

\subsection{Dissection and Microbiology}

Larvae were weighed, chilled in a freezer for a few minutes to briefly anaesthetize them, and surface sterilized for two minutes in $50 \%$ bleach and two rinses of ultrafiltered water, and then dissected under sterile conditions under a laminar flow hood. To culture microbes, incisions were made into the midgut and hindgut paunches (Figure 1) of six larvae and a weighed amount ( $\leq 500 \mathrm{mg}$ ) of contents was added to $1 \mathrm{~mL}$ of $10 \mathrm{mM}$ phosphate buffer solution. Five serial 10-fold dilutions were spread onto plates of HiMedia ${ }^{\circledR}$ Nutrient Agar (HiMedia Laboratories Pvt.Ltd., Dindhori, Nashik, India) and incubated aerobically at $30^{\circ} \mathrm{C}$ for $72 \mathrm{~h}$. Individual microbe colonies were isolated into pure cultures on the basis of morphology and counted across all plates with countable dilutions. The $\mathrm{pH}$ of the gut content was measured with a Hydrion ${ }^{\circledR} \mathrm{pH}$ strip (Micro Essential Laboratory Inc., Brooklyn, NY, USA) dipped into the lumen. Samples of gut contents were briefly examined under a compound microscope to observe microbes.

\subsection{Cellulase Testing}

To test the gut for cellulase activity, petri dishes were made with $50 \mathrm{mM}$ citrate-phosphate buffer solution, $1 \%$ agar, and $0.2 \%$ carboxymethyl cellulose (CMC) (Fisher Scientific, Leicestershire, UK) or xylan from corn core (Tokyo Chemical Industry, Tokyo, Japan) as the only carbon source, with pHs of 5, 6.5, and 7.6. From a dissected larva, fresh gut luminal fluid was pipetted from incisions in the six gut sections as depicted in Figure 1 into small wells cut into the plates with a pipette tip, using 5 and $10 \mu \mathrm{L}$ of fluid for CMC and xylan, respectively. Cellulase from Asperillus niger (Tokyo Chemical Industry, Tokyo, Japan) was used as a positive control, and purified water as a negative control. Plates were incubated at $40{ }^{\circ} \mathrm{C}$ in a plastic bag to retain moisture for $48 \mathrm{~h}$. The plates were then flooded with 0.1\% Congo Red (Acros Organics, Geel, Belgium) (Color Index No. 22120) in $0.1 \mathrm{M}$ Tris-HCl buffer (Bioman Scientific Co., Ltd., Jhonghe City, Taiwan) pH 8.0 for $1 \mathrm{~h}$ on a shaking plate and then destained in $1 \mathrm{M} \mathrm{NaCl}$ (BioShop ${ }^{\circledR}$ Canada Inc., Burlington, ON, Canada) for at least $1 \mathrm{~h}$. Clear zones indicated cellulase activity.

To test for cellulolytic microbes, $50 \mu \mathrm{L}$ from the initial 1-mL sample of midgut or hindgut gut contents as used for the nutrient agar plates were plated onto $\mathrm{CMC}$ agar at $\mathrm{pH} 5$ and allowed to grow. After colonies were picked for isolation onto CMC agar, the plates were flooded with Congo Red and destained [21]. Halos of clearing in the plates qualitatively indicate extracellular cellulase activity. To detect intracellular cellulolytic activity for certain target microbes, the tetrazolium blue method for determining reducing sugars was used [22,23]. Microbes were grown in HiMedia ${ }^{\circledR}$ nutrient broth at room temperature for $24 \mathrm{~h}$, then diluted to match a McFarland 5 standard (Creative Media Plate ${ }^{\circledR}$, New Taipei City, Taiwan) in optical density. This sample was diluted 1/100 in ultrafiltered water, and $10 \mu \mathrm{L}$ of this dilution were mixed with $100 \mu \mathrm{L}$ of $1 \% \mathrm{CMC}$ in $100 \mathrm{mM}$ sodium acetate buffer (pH 5.5), vortexed, and incubated at $37^{\circ} \mathrm{C}$ for $13 \mathrm{~min}$. To stop the reaction, $0.8 \mathrm{~mL}$ of tetrazolium blue reagent were added and the mixture boiled for five minutes. Absorbance at $470 \mathrm{~nm}$ was measured using a Libra S2 spectrophotometer (Biochrom Ltd., Cambridge, UK) and the reducing sugar concentration calculated by comparison with glucose solution standards. Broth without microbes was the negative control, and a cellulolytic strain of Chaetomium globosum (Sordariomycetes: Sordariales: Chaetomiaceae) maintained in the lab was the positive control. 


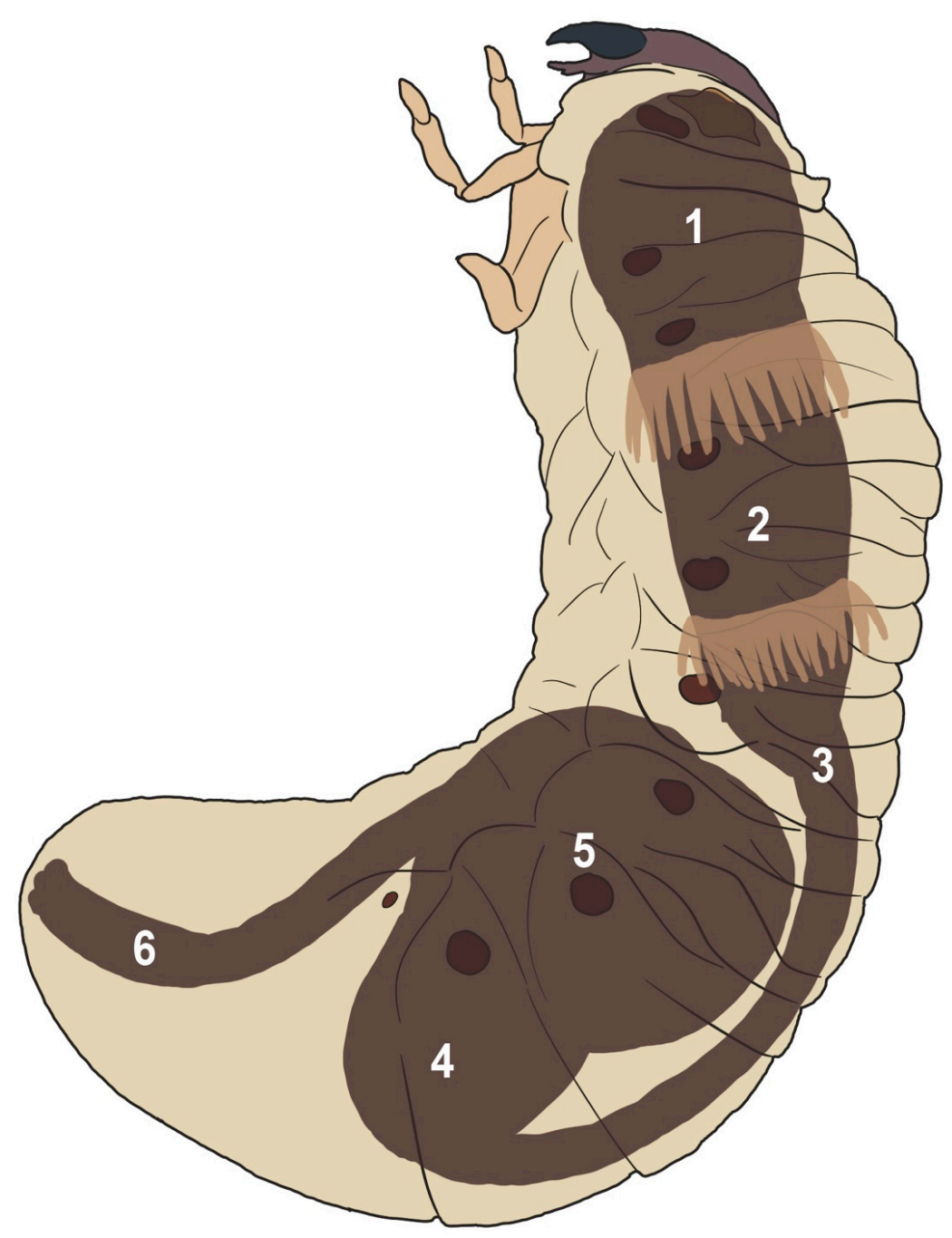

Figure 1. Diagram of the digestive tract of a larval Oryctes rhinoceros. The numbering corresponds to the cellulase and xylanase tests in Figure 2. The foregut is short to nonexistent. Two rows of gastric cecae ring the midgut (1-3). Our midgut samples were taken from an incision made between these rings (Section 3). The hindgut (4-6) contains a large bulbous fermentation chamber whose entrance from the midgut is posterior to its exit, meaning gut contents flow through the hindgut in a posterior-anterior direction. Our hindgut samples were taken from an incision in the middle of this paunch (5). Figure Credit: Sonja Pinck. 


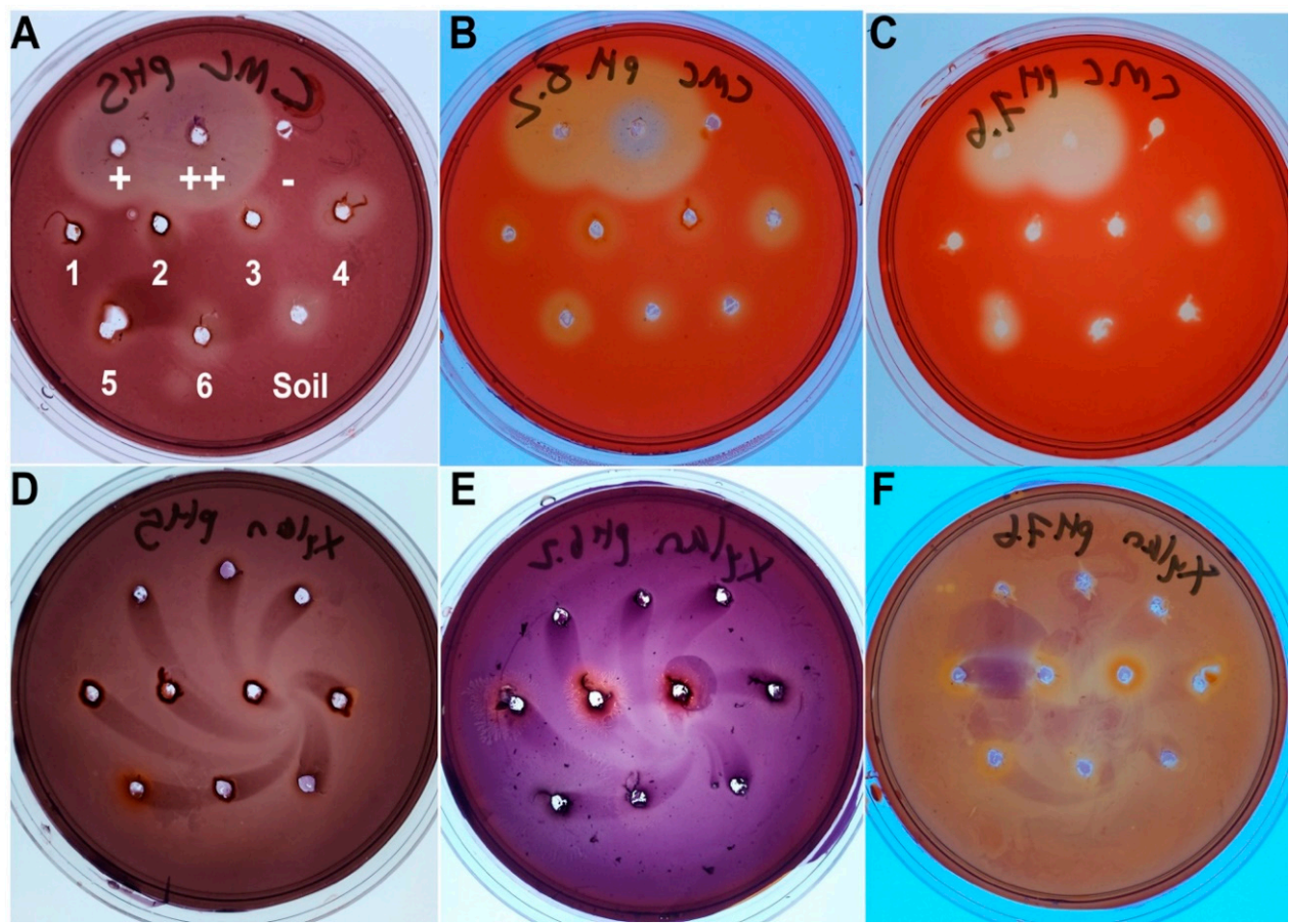

Figure 2. Cellulase and xylanase tests of the Oryctes rhinoceros gut at different pHs. Clearings in the Congo Red-stained plates indicate positive cellulase or xylanase activity. The positive control is commercial cellulase from Asperillus niger (TCI, Japan): (+) is $0.029 \mathrm{U},(++)$ is $0.29 \mathrm{U}$. Note that this cellulase is not xylanolytic. The negative control (-) is deionized water. The numbering corresponds to the sections in Figure 1, with 1-3 from the midgut and 4-6 from the hindgut. The other sample is from the soil in which the larvae live. (A) Carboxymethyl cellulose CMC plate at pH 5. (B) CMC plate at $\mathrm{pH}$ 6.5. (C) CMC plate at $\mathrm{pH}$ 7.6. (D) Xylan plate at $\mathrm{pH}$ 5. (E) Xylan plate at $\mathrm{pH}$ 6.5. (F) Xylan plate at 7.6. Photo Credit: Matan Shelomi.

\subsection{Cultured Microbe Identification}

Clones of individually cultured microbes were examined under a microscope, and a small isolated colony's worth of cells lysed in $50 \mu \mathrm{L}$ of nuclease-free water by heating at $95^{\circ} \mathrm{C}$ for $10 \mathrm{~min}$. Bacteria were identified using the $16 \mathrm{~S}$ gene and fungi with the 18S, 26S (D1/D2), and internal transcribed spacer (ITS) (ITS1-5.8S-ITS2) genes using the primers in Supplementary Materials Table S1. The PCR conditions were $95^{\circ} \mathrm{C}$ for $3 \mathrm{~min}$; 35 cycles of $95{ }^{\circ} \mathrm{C}$ for $45 \mathrm{~s}, 52^{\circ} \mathrm{C}$ for $90 \mathrm{~s}$, and $72{ }^{\circ} \mathrm{C}$ for $60 \mathrm{~s} ; 72{ }^{\circ} \mathrm{C}$ for $10 \mathrm{~min}$; and a hold at $4{ }^{\circ} \mathrm{C}$. PCR products were run through an agarose gel and DNA extracted from the cut bands using a QIAquick ${ }^{\circledR}$ Gel Extraction Kit (Qiagen, Hilden, Germany). The PCR products were sequenced at the Sanger DNA Sequencing Core Lab of the Center for Biotechnology at National Taiwan University with an Applied Biosystems ${ }^{\circledR} 3730$ analyzer (Thermo Fisher Scientific, Waltham, MA, USA). Forward and reverse sequences were merged using EMBOSS: merger [24] and identified using BLASTn and the 16S RNA database for bacterial sequences, or the appropriate fungal RNA database (ITS, 26S) for yeasts, searching only among type strain sequences [25]. For microbes whose identity required further validation, sequences for the respective barcoding genes from type strains of related species were downloaded from the DNA Data Bank of Japan (DDBJ) and the National Center for Biotechnology Information (NCBI) and used to make neighbor-joining trees. A representative strain of each microbe species was deposited at the Bioresource Collection and Resource Center (BCRC) in Hsinchu, Taiwan.

\subsection{Metabarcoding}

For complete bacterial microbiome analysis, DNA was extracted from $250 \mathrm{mg}$ of midgut or hindgut contents from each individual larva using a Geneaid ${ }^{\circledR}$ Presto $^{\mathrm{TM}}$ Soil DNA kit (Geneaid Biotech Ltd., 
New Taipei City, Taiwan). This was done successfully (meaning, the extracted DNA passed quality to control for metabarcoding) for 16 larvae separately, including 4 of those from whose gut contents an aliquot was used for culturing. DNA was also successfully extracted from the fat bodies of four larvae, and from triplicate samples of coconut pulp from the larval rearing container. Quality control consisted of a NanoDrop (OD260/OD280) test, Agarose Gel Electrophoresis testing of DNA degradation and potential contamination, and Qubit 2.0 DNA concentration quantification. The extracted DNA was sequenced by BioTools Co. Ltd. (New Taipei City, Taiwan). Libraries were constructed on a paired-end Illumina HiSeq platform to generate 250-bp paired-end raw reads of the V3/V4 region of the $16 \mathrm{~S}$ gene, which were merged using FLASH [26], and transformed to sequenced reads by base calling.

Results were analyzed via QIIME2 v2019.7 [27]. Denoising was done with deblur, discarding any features whose abundance in any sample was $<1 \%$ of the average total reads for the samples. Samples with only one operational taxonomic unit (OTU) and OTUs present in only one sample were discarded. Sample microbial diversity was calculated with the minimum sampling depth to keep all samples (1553), which, for this data set, was still enough for the alpha rarefaction curves to plateau, meaning the sampling depth was sufficient to assess the species richness of the samples. OTUs were identified using the SILVA 138 99\% OTUs Classifier for 16S [28,29]. The QIIME2 program ancom (analysis of composition of microbiome) was used to compare the microbiomes between the midgut and hindgut samples via differential abundance testing.

\section{Results}

\subsection{Anatomy}

A diagram of the larval digestive tract is present in Figure 1. The foregut is limited to a short pharynx or esophagus leading directly and with no obvious demarcation to a swollen cylindrical midgut. Two rings circle the midgut, each of approximately 30 cecae pointing posteriorly, approximately $1.5 \mathrm{~mm}$ long, and filled with a dark substance. The midgut narrows considerably before entering the hindgut, which starts with a bulbous swollen paunch. Notably, the gut forms an S-bend, with the "entrance" of the hindgut almost at the posterior end of the insect, while the "exit" of the hindgut is anterior nearer to where the midgut first thins. Thus, the contents of the hindgut are flowing in a posterior-to-anterior direction. The contents of both the midgut and the hindgut are dark brown with the consistency of fine wet soil. The hindgut exits into a thin "rectum" that exits through the anus. The mass of the hindgut is approximately $150 \%$ the mass of the midgut. The $\mathrm{pH}$ of the midgut varied considerably, averaging $6.67 \pm 2.08$, while the hindgut $\mathrm{pH}$ varied less drastically, averaging $6.92 \pm 0.88$. Neither section was consistently more or less acidic than the other. The rest of the body of the larva is comprised almost entirely of diffuse white fat body. Bacteria are visible in the midgut and hindgut contents, while sparse protozoa were visible in the hindgut.

\subsection{Cellulase and Xylanase Activity of the Gut}

Testing of the six gut sections identified in Figure 1 (midgut 1-3 and hindgut 4-6) plus a sample of soil in which the larvae lived showed compartmentalization of plant cell wall degradation was conducted (Figure 2). Cellulolytic activity was detected in all samples, including the soil, at pH 5 and 6.5, but limited to the hindgut paunch (Sections 4 and 5) at $\mathrm{pH}$ 7.6. Xylanolytic activity was limited to the hindgut paunch at $\mathrm{pH} 5$, limited to the midgut at $\mathrm{pH} 6.5$, and detected somewhat equally in Sections $1-5$ at $\mathrm{pH}$ 7.6.

\subsection{Cultured Microbes}

The microbes found in the gut samples are listed in Table 1, with identifications based on sequence similarity to the type specimens in the $16 \mathrm{~S}$ ribosomal RNA sequence database. The bacteria Bacillus cereus could be cultured from five out of six larval hindguts and three midguts. Lysinibacillus fusiformis was found in four hindguts and only one midgut. Citrobacter koseri, Comamonas nitrativorans, 
and an unidentifiable genus in the Enterobacteriaceae (with $97.74-97.75 \% 16 \mathrm{~S}$ sequence similarity to Salmonella enterica subsp. arizonae strain DSM 9386, Citrobacter youngae strain GTC 1314, and Enterobacter cloacae strain DSM 30054) were found in the midguts and/or hindguts of three larvae. The former was the most abundant gut microbe in both the midgut and the hindgut by an order of magnitude. The other bacteria were only ever cultured from individual larvae. A fungus identified as Candida xylanilytica was found in five midgut and three hindgut samples. Because the genomic sequence of this cellulolytic Candida xylanilytica strain's 18S, ITS (ITS1, 5.8S, and ITS2), and D1/D2 regions ambiguously identified it as either Candida xylanilytica or Spathaspora sp. (Ascomycota, Saccharomycetes, Debaryomycetaceae), neighbor-joining trees were made for those sequences and those of related species of Candida or Spathaspora to verify the identification. The results confirmed the cellulolytic yeasts isolated from the larval guts are strains of Candida xylanilytica (Figure 3, Supplementary Materials Figures S1 and S2).

Table 1. Microbes cultured from the midguts and hindguts of larval Oryctes rhinoceros. These microbes were isolated from six larvae whose gut contents were plated into nutrient agar (NA) and carboxymethyl cellulose agar (CMC). Microbe identity given is the closest type specimen in the NCBI RNA database, with sequence similarity in parentheses, except for an Enterobacteriaceae that could not be determined (see results). Microbial density as colony forming units (CFUs) per milligram of midgut or hindgut content is estimated by averaging the CFU/mg of each serial dilution plate with a countable number of colonies of said species, which was only done for NA plates. The ranges varied within an order of magnitude. The number of midgut samples, hindgut samples, and larvae out of six is given. A dash (-) means CFU could not be calculated.

\begin{tabular}{|c|c|c|c|c|}
\hline \multirow{2}{*}{ Identity } & \multirow{2}{*}{ Agar } & \multicolumn{2}{|c|}{ Mean CFU/mg (\# Samples) } & \multirow{2}{*}{$\begin{array}{c}\text { \# of } \\
\text { Larvae }\end{array}$} \\
\hline & & Midgut & Hindgut & \\
\hline Bacillus cereus ATCC 14579 (99.72) & $\mathrm{NA}, \mathrm{CMC}$ & $4.7 \times 10^{5}(3)$ & $5.5 \times 10^{5}(5)$ & 5 \\
\hline Bacillus proteolyticus MCCC 1A00365 (99.79) & NA & $7.2 \times 10^{5}(1)$ & 0 & 1 \\
\hline Bacillus toyonensis BCT-7112 (99.93) & NA & $5.0 \times 10^{4}(1)$ & $1.5 \times 10^{7}(1)$ & 1 \\
\hline * Candida tropicalis ATCC 750 (99.65) & $\mathrm{CMC}$ & $-(1)$ & 0 & 1 \\
\hline * Candida xylanilytica KU-Xn11T (99.85) & $\mathrm{NA}, \mathrm{CMC}$ & $9.9 \times 10^{6}(5)$ & $3.5 \times 10^{7}(3)$ & 5 \\
\hline Citrobacter koseri LMG 5519 (99.44) & $\mathrm{NA}, \mathrm{CMC}$ & $-(2)$ & $3.1 \times 10^{8}(2)$ & 3 \\
\hline Comamonas nitrativorans 23310 (99.15) & $\mathrm{NA}, \mathrm{CMC}$ & $-(2)$ & $7.4 \times 10^{7}(3)$ & 3 \\
\hline Diaphorobacter aerolatus 8604S-37 like (97.38) & CMC & 0 & $-(1)$ & 1 \\
\hline Enterobacteriaceae $(97.75)$ & $\mathrm{NA}, \mathrm{CMC}$ & $3.5 \times 10^{7}(3)$ & $1.4 \times 10^{7}(3)$ & 3 \\
\hline Klebsiella pneuomoniae DSM 30104 (99.44) & $\mathrm{NA}, \mathrm{CMC}$ & $1.1 \times 10^{6}(1)$ & $6.8 \times 10^{7}(1)$ & 1 \\
\hline Kluyvera georgiana ATCC 51603 (99.14) & $\mathrm{NA}, \mathrm{CMC}$ & $3.5 \times 10^{6}(1)$ & $3.9 \times 10^{5}(1)$ & 1 \\
\hline Lactococcus lactis NBRC 100933 like (96.45) & NA & $2.6 \times 10^{6}(1)$ & 0 & 1 \\
\hline Lysinibacillus fusiformis NBRC 15717 (99.30) & $\mathrm{NA}, \mathrm{CMC}$ & $1.7 \times 10^{5}(1)$ & $1.5 \times 10^{5}(4)$ & 4 \\
\hline $\begin{array}{c}\text { Pseudomonas citronellolis NBRC } 103043 \\
\text { (98.59) }\end{array}$ & $\mathrm{NA}, \mathrm{CMC}$ & 0 & $5.0 \times 10^{6}(1)$ & 1 \\
\hline $\begin{array}{c}\text { Staphylococcus epidermidis NBRC } 100911 \\
\text { (99.23) }\end{array}$ & NA & $5.0 \times 10^{3}(1)$ & 0 & 1 \\
\hline $\begin{array}{l}\text { Staphylococcus hominis GTC } 1228(99.65 \%) \\
\text { Streptomyces costaricanus NBRC } 100773\end{array}$ & NA & 0 & $1.7 \times 10^{6}(1)$ & 1 \\
\hline $\begin{array}{c}\text { or } \\
\text { S. murinus NBRC } 14802 \text { (99.64) }\end{array}$ & $\mathrm{CMC}$ & - (1) & $-(1)$ & 1 \\
\hline * Trichoderma virens DAOM 164916 (99.19) & CMC & $-(1)$ & 0 & 1 \\
\hline
\end{tabular}

* Fungi. \# Number.

Twelve microbe species could grow on CMC agar (Table 1), including four strains, each found only in one larva, that were not found growing on nutrient agar plates. Only some Candida xylanilytica strains and the Candida tropicalis and Streptomyces costaricanus/murinus strains produced clearings in the agar after staining with Congo Red and destaining with $\mathrm{NaCl}$. Seven Candida xylanilytica strains were tested for cellulolytic activity with the tetrazolium blue method, and all had cellulase activity 
(Table 2) regardless of whether they tested positive for extracellular cellulase activity with the Congo Red assays.

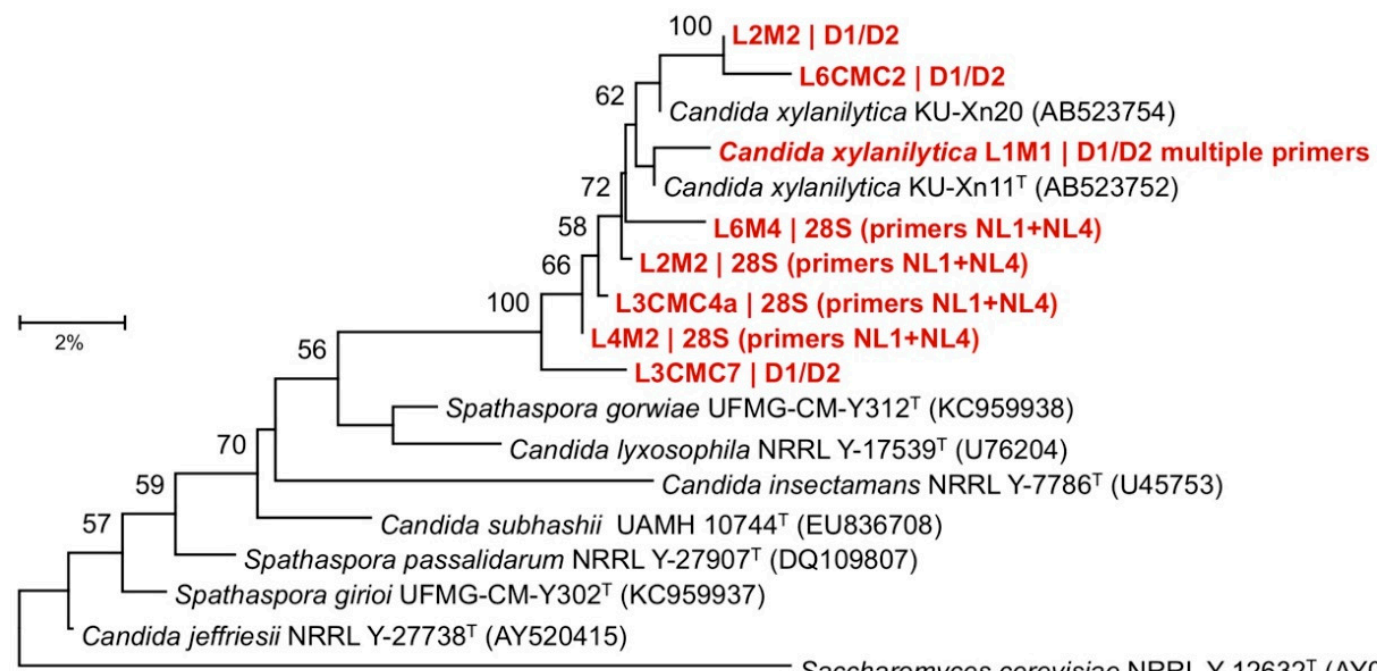

Saccharomyces cerevisiae NRRL Y-12632 ${ }^{\top}$ (AY048154)

Figure 3. Phylogenetic tree based on D1/D2 region sequence analysis. Samples in red are putative Candida xylanolytica strains isolated from larval midguts. The tree was constructed by the neighbor-joining method and Saccharomyces cerevisiae was used as the outgroup. Bootstrap values (expressed as percentages of 1000 replications) greater than $50 \%$ are shown at branch points. Scale bar represents $2 \%$ sequence divergence. T: type strain. Figure Credit: Ming-Ju Chen.

Table 2. Candida xylanilytica strain cellulase test with tetrazolium blue method. Microbes were reared in nutrient broth, then a sample incubated with CMC in a buffer for $13 \mathrm{~min}$, boiled with tetrazolium blue reagent for $5 \mathrm{~min}$ to stop the reaction, and the color change measured using a spectrophotometer. By calibrating the machine with known concentrations of glucose, the concentration (M) of reducing sugars can be quantified. The samples are Candida xylanilytica strains from Oryctes rhinoceros larvae. The positive control is Chaetomium globosum. The negative control is sterile nutrient broth.

\begin{tabular}{ccc}
\hline Sample & Absorbance at $\mathbf{4 7 0} \mathbf{~ n m}$ & M Sugars \\
\hline L1M1 & 1.23 & 0.1665 \\
L2M2 & 1.41 & 0.4398 \\
L3CMC4A & 1.19 & 0.1342 \\
L3CMC7 & 1.11 & 0.0871 \\
L4M2 & 0.99 & 0.0456 \\
L6M4 & 1.18 & 0.1271 \\
L6CMC2 & 1.36 & 0.3358 \\
Positive control & 1.3 & 0.2429 \\
Negative control & 0.54 & 0.0040 \\
\hline
\end{tabular}

\subsection{S Microbial Profiling}

The raw metabarcoding reads are available on the NCBI Sequence Read Archive, GenBank Accession Numbers SRR11191467-SRR11191507. A total of 2,765,840 sequence reads were obtained in the raw data (min 31,370, max 86,727, mean 67,460). Following quality control, alpha rarefaction at several sampling depths using QIIME2 confirmed that our sequencing had reached a plateau for all samples, with plateaus reached at $<200$ sequences (Supplementary Materials Figure S3). QIIME2 identified 65 bacterial OTUs from the samples sent for metabarcoding, of which 33 were found in more than one sample (Supplementary Materials Data Sheet S1). ANCOM analysis using QIIME2 revealed no significant differences between the larval midgut and hindgut microbiomes $(\mathrm{W}=0$ for all OTUs). 
An OTU identified as Paracoccus was detected in fat body, hindgut, and especially midgut samples of most larvae and with higher abundance than any other OTU, though not found in the soil. Citrobacter koseri OTUs were similarly found in gut and fat body samples of several larvae and in high abundance, and not found in the soil. Notably, larvae with Paracoccus sp. as the dominant microbe almost always lacked Citrobacter koseri, and vice versa. Lysinibacillus was found in only three larval midguts, none of which were the ones also used for culturing. A putative new genus of Anaeroplasma-like Acholeplasmataceae was found in the midguts only of half the samples, and a putative new species of Erysipelothrix in the midguts of five individuals and fat body of one. A species of Proteiniphilum was found in four hindguts only but in low abundance. QIIME2 identified two OTUs as new genera of Oscillospiraceae, each in four separate hindguts, though these could possibly be a single species found in eight larval hindguts that QIIME2 mistakenly split. Common OTUs found in both midguts and hindguts were Dysgonomonas spp. in six samples and a new genus of Rhodocyclaceae in five. In contrast to the culturing results, no Bacillus cereus was found in the microbiome data, and the only Enterobacteriaceae was Citrobacter koseri.

\section{Discussion}

Microbes were cultured from a total of 6 larvae and metabarcoding from 16 larvae from the same coconut grove, which is a comparable sample size to those of similar studies that used typically no more than 5 samples [4,30-35], and is thus more than adequate to draw conclusions for beetles in this location. While culturing can only reveal a small portion of the microbial diversity of a sample, and aerobic culturing would miss the anaerobic microbes thought to dominate in an insect gut, the culturing data from this study is still fully comparable to culturing data performed by other researchers worldwide, and when combined with the metabarcoding can produce a more reliable picture of the true microbiome than either method alone.

Bacillus cereus is likely a ubiquitous microbial resident of the Oryctes rhinoceros digestive tract, as it or other members of the notoriously genetically similar Bacillus genus [36] have also been found in all previous studies of this species' microbiomes [13,16-19]. While none of our strains produced cellulase with the Congo Red assay, cellulolytic strains of $B$. cereus exist, so it could provide symbiotic digestive functions to Oryctes. However, B. cereus is an extremely cosmopolitan species associated with a wide variety of animal digestive tracts [37-39], and so less likely to be an essential microbial symbiont for O. rhinoceros (unless one assumes that it plays important roles in an extremely diverse set of vertebrate and invertebrate organisms, which is indeed possible). More disconcerting is the absence of $B$. cereus from the molecular barcoding data; however, it is not unusual for the microbes found in culturing to differ from those in culture-independent data from the same individuals [40]. The alternative explanation is that $B$. cereus is a contaminant of the laboratory equipment involved in culturing but that is unlikely given its presence in all past Oryctes rhinoceros work from other laboratories [17-19]. Testing the B. cereus strains for extra- and intracellular cellulolytic activity would verify if they can help the larvae digest wood, and will be done in the future. Regardless of those results, these strains are almost certainly orally acquired and possibly transient gut microbes passing through the gut with the food.

Citrobacter koseri is the other microbe consistently found in Oryctes rhinoceros microbiome studies [13,17], and was the most abundant microbe in our samples in terms of CFU per mg, but it too is cosmopolitan and frequently found to be associated with insect digestive tracts [37]. Some strains of Citrobacter koseri and other Enterobacteriaceae can produce cellulases under certain conditions [41]. Paracoccus was found in the microbiomes of larvae that did not have Citrobacter koseri, and which were collected on a different day (Supplementary Materials Data Sheet S1). An anaerobic cellulolytic Paracoccus species has been detected in a scarab beetle gut before [37]. Thus, while these microbes may well have digestive roles in Oryctes rhinoceros, not enough evidence exists at this time to claim this with certainty. Even if they are cellulolytic, these microbes are likely orally acquired and possibly transient 
gut microbes passing through the gut with the food, although none were found in the DNA extracted from the coconut pulp itself (Supplementary Materials Data Sheet S1).

While several microbes grew on CMC agar, little evidence of extracellular cellulase production was found using the Congo Red assays except for some Candida xylanilytica strains. Testing for cellulase activity with the tetrazolium blue method was only performed for Candida xylanilytica, and yielded positive results. This recently discovered fungus [42] is related to the Spathaspora clade known to be associated with rotting wood and wood-boring insects [43], and likely provides enzymatic digestion for the beetle, but whether this function is essential to the fitness of the species is presently unknowable. This microbe was found in the midguts and hindguts of almost all beetles in this study but had not been noted in previous studies, largely because they focused on bacteria. Future collection efforts across Taiwan are underway to determine how widely spread this yeast is in Oryctes rhinoceros digestive tracts. Cellulolytic strain L1M1 of the Candida xylanilytica is stored and publicly available at the Bioresource Collection and Research Center in Hsinchu, Taiwan (BCRC: 23544). Because this metabarcoding study only looked at bacterial diversity, it missed the Candida xylanolytica along with any protozoa in the samples, some of which were visible in the hindgut samples under a microscope (albeit in far lower abundance compared to an equivalent sample from a termite). Future projects focusing on fungal and protozoan diversity in Oryctes are thus justified.

Lysinibacillus fusiformis (syn. Lysinibacillus sphaericus, Bacillus fusiformis, Bacillus sphaericus) was commonly found, yet is also cosmopolitan, and a known insect pathogen [44]. While cultured often, it was less abundant in the metagenomic data, suggesting it is not as widely conserved in the larval guts. The putative symbionts of Proteiniphilum, Erysipelothrix, and the unidentifiable Oscillospiraceae and Acholeplasmataceae are seemingly specific to either the midgut or the hindgut and could be linked to the different $\mathrm{pH}$ optimal for cellulolytic activity in the midgut and hindgut; however, they are not known from previous molecular datasets. Likewise, several microbes identified in previous work as being possible symbionts were not observed in this study: namely Desulfovibrio sp., Treponema sp., Endomicrobium sp., and Bastocystis sp. [13]. Comparative microbiome analysis of samples found across greater geographic distance and feeding on different plants are necessary to separate transient microbes picked up from the specific location where a larva feeds from genuine symbionts, and such work is presently ongoing. One should also remember that not all organisms have an obligate microbiome [45], and transient or environmentally acquired gut microbes can still have powerful impacts on insect survival and fitness, so final conclusions on the importance of microbes to an insect's fitness will require assays with antibiotics or axenically reared insects.

The function of the two rings of midgut cecae remains unknown, but the data does not suggest a microbe-related hypothesis for their function. The midgut and hindgut are clearly separated from each other, and their gut fluids are cellulolytic at different $\mathrm{pH}$ levels, suggesting compartmentalized digestion [46]. The large paunch-like hindgut of the beetles and the greater cellulolytic and xylanolytic ability detected there suggest a microbial fermentation chamber, and the S-bend of the gut would increase the transit time for food to provide increased time for digestion [46]. However, the absence of significant differences in the $\mathrm{pH}$ or bacterial diversity of the midgut and hindgut in Oryctes rhinoceros cast doubt on whether microbial fermentation is critical for cellulase digestion in the gut the way it is in lower termites. Rather, the gut may be an opportune location for cellulolytic microbes found in the food to continue their activity, while, otherwise, the beetle's digestion is symbiont independent, using the endogenous cellulase identified in the Oryctes rhinoceros transcriptome [13]. Microbe-independent digestion is surprisingly common in insects [45], so insects should not automatically be assumed to have symbionts. The lack of opportunities for horizontal microbe transfer in these non-colonial beetles would preclude the evolution of obligate symbioses like in the termite hindgut; however, the existence of vertically transmitted microbes cannot be ruled out at this time, and the hypothesis that cellulolytic B. cereus and Candida xylanilytica play digestive functions in the insect is still supportable. Molecular analysis of the microbiome, if present, of the adult ovaries would quickly identify potential vertically 
transmitted microbes, and fluorescent in situ hybridization of these species would better visualize in what gut areas or tissues these microbes are found [47].

\section{Conclusions}

The digestive system of the Oryctes rhinoceros larva includes a midgut with cecae and a swollen hindgut paunch. Both gut sections show cellulolytic and xylanolytic activity, and the bacterial populations in the two gut sections are similar. Dominant microbes include Citrobacter koseri, Bacillus cereus, an unculturable Paracoccus sp., and the fungus Candida xylanolytica. Some of these microbes are likely acquired from the environment given their known cosmopolitanism, but all have documented or demonstrated cellulolytic abilities, so whether they are commensalists or mutualists that help the beetle larvae digest their food remains to be proven.

Supplementary Materials: The following are available online at http://www.mdpi.com/2075-4450/11/11/0782/s1, Figure S1: Phylogenetic tree based on 18S rRNA sequence analysis, Figure S2: Phylogenetic tree based on ITS1-5.8S-ITS2 region sequence analysis, Figure S3: Alpha rarefaction curve for metabarcoding using Faith's PD metric, confirming plateaus were reached at our sequencing depth of 1553 for all samples, Data Sheet S1: Results of the Oryctes rhinoceros metabarcoding study, Table S1: Primers used to identify cultured microbes.

Author Contributions: Conceptualization, M.S.; methodology, M.S. and M.-J.C.; validation M.-J.C.; formal analysis, M.S.; investigation, M.S.; resources, M.S.; data curation, M.S.; writing-original draft preparation, M.S.; writing-review and editing, M.S. and M.-J.C.; project administration, M.S.; funding acquisition, M.S. Both authors have read and agreed to the published version of the manuscript.

Funding: This research was funded by the Taiwan Ministry of Science and Technology, grant numbers 106-2311-B-002-002-MY3 and 109-2311-B-002-016-MY3.

Acknowledgments: Special thanks are given to Yu-Fang Tsai (NTU) for insect collection, Marwin Fernandez (NTU) for microbiology work, Sonja Pinck (California State University, Monterey Bay) for figure illustration, and to Chung-Ann Wang.

Conflicts of Interest: The authors declare no conflict of interest. The funders had no role in the design of the study; in the collection, analyses, or interpretation of data; in the writing of the manuscript, or in the decision to publish the results.

\section{References}

1. Calderón-Cortés, N.; Quesada, M.; Watanabe, H.; Cano-Camacho, H.; Oyama, K. Endogenous Plant Cell Wall Digestion: A Key Mechanism in Insect Evolution. Annu. Rev. Ecol. Evol. Syst. 2012, 43, 45-71. [CrossRef]

2. Ni, J.; Tokuda, G. Lignocellulose-degrading enzymes from termites and their symbiotic microbiota. Biotechnol. Adv. 2013, 31, 838-850. [CrossRef]

3. Wang, H.; Rehman, K.u.; Liu, X.; Yang, Q.; Zheng, L.; Li, W.; Cai, M.; Li, Q.; Zhang, J.; Yu, Z. Insect biorefinery: A green approach for conversion of crop residues into biodiesel and protein. Biotechnol. Biofuels 2017, 10, 304. [CrossRef]

4. Mohammed, W.S.; Ziganshina, E.E.; Shagimardanova, E.I.; Gogoleva, N.E.; Ziganshin, A.M. Comparison of intestinal bacterial and fungal communities across various xylophagous beetle larvae (Coleoptera: Cerambycidae). Sci. Rep. 2018, 8, 10073. [CrossRef]

5. Busch, A.; Danchin, E.G.; Pauchet, Y. Functional diversification of horizontally acquired glycoside hydrolase family 45 (GH45) proteins in Phytophaga beetles. BMC Evol. Biol. 2019, 19, 100. [CrossRef]

6. Sudakaran, S.; Kost, C.; Kaltenpoth, M. Symbiont Acquisition and Replacement as a Source of Ecological Innovation. Trends Microbiol. 2017, 25, 375-390. [CrossRef]

7. Jackson, T.A.; Crawford, A.M.; Glare, T.R. Oryctes virus-time for a new look at a useful biocontrol agent. J. Invertebr. Pathol. 2005, 89, 91-94. [CrossRef] [PubMed]

8. Bedford, G.O. Biology, ecology, and control of palm rhinoceros beetles. Annu. Rev. Entomol. 1980, 25, 309-339. [CrossRef]

9. Khoo, K.C.; Ooi, P.A.C.; Ho, C.T. Crop Pests and Their Management in Malaysia; Tropical Press: Kuala Lumpur, Malaysia, 1991; pp. ix +242. 
10. Huger, A.M. The Oryctes virus: Its detection, identification, and implementation in biological control of the coconut palm rhinoceros beetle, Oryctes rhinoceros (Coleoptera: Scarabaeidae). J. Invertebr. Pathol. 2005, 89, 78-84. [CrossRef] [PubMed]

11. Yang, J.; Yamamoto, M.; Ishibashi, J.; Taniai, K.; Yamakawa, M. Isolation, cDNA cloning and gene expression of an antibacterial protein from larvae of the coconut rhinoceros beetle, Oryctes rhinoceros. Eur. J. Biochem. 1998, 255, 734-738. [CrossRef] [PubMed]

12. Tomie, T.; Ishibashi, J.; Furukawa, S.; Kobayashi, S.; Sawahata, R.; Asaoka, A.; Tagawa, M.; Yamakawa, M. Scarabaecin, a novel cysteine-containing antifungal peptide from the rhinoceros beetle, Oryctes rhinoceros. Biochem. Biophys. Res. Commun. 2003, 307, 261-266. [CrossRef]

13. Shelomi, M.; Lin, S.-S.; Liu, L.-Y. Transcriptome and microbiome of coconut rhinoceros beetle (Oryctes rhinoceros) larvae. BMC Genom. 2019, 20, 957. [CrossRef] [PubMed]

14. Desai, A.; Bhamre, P. Diversity of gut bacterial fauna of Oryctes monocerus linnaeus (Coleoptera: Scarabaeidae). Bionano Front. 2012, 5, 1-4.

15. El-Sayed, W.S.; Ibrahim, R.A. Diversity and phylogenetic analysis of endosymbiotic bacteria of the date palm root borer Oryctes agamemnon (Coleoptera: Scarabaeidae). BMC Microbiol. 2015, 15, 88. [CrossRef]

16. Sowole, A.D.; Awojobi, K.O.; Agboola, F.K. Purification and Characterization of Partially Purified Cellulolytic Enzyme Produced by Bacillys brevis Isolated from the Gut of Larva of Beetle, Oryctes rhinoceros (L.). Ph.D. Thesis, Obafemi Awolowo University, Ife, Nigeria, 2015.

17. Sari, S.L.A.; Pangastuti, A.; Susilowati, A.; Purwoko, T.; Mahajoeno, E.; Hidayat, W.; Mardhena, I.; Panuntun, D.F.; Kurniawati, D.; Anitasari, R. Cellulolytic and hemicellulolytic bacteria from the gut of Oryctes rhinoceros larvae. Biodiversitas 2016, 17, 78-83. [CrossRef]

18. Dini, I.R.; Wawan, W.; Hapsoh, H.; Sriwahyuni, S. Isolation and Identification of Cellulolytic and Lignolytic Bacteria from the Gut Oryctes rhinoceros L. Larvae Decomposition of Oil Palm Empty Fruit Bunches. Indones J. Agric. Res. 2018, 1, 193-203. [CrossRef]

19. Pradeep Kumar, R.; John, A.; Kumar, P.; Dinesh Babu, K.V.; Evans, D.A. Larvicidal efficacy of Adiantobischrysene from Adiantum latifolium against Oryctes rhinoceros through disrupting metamorphosis and impeding microbial mediated digestion. Pest Manag. Sci. 2018, 74, 1821-1828. [CrossRef]

20. Beaudoin-Ollivier, L.; Prior, R.N.; Laup, S. Simplified field key to identify larvae of some rhinoceros beetles and associated scarabs (Coleoptera: Scarabaeoidea) in Papua New Guinea coconut developments. Ann. Entomol. Soc. Am. 2000, 93, 90-95. [CrossRef]

21. Teather, R.M.; Wood, P.J. Use of Congo red-polysaccharide interactions in enumeration and characterization of cellulolytic bacteria from the bovine rumen. Appl. Environ. Microbiol. 1982, 43, 777-780. [CrossRef]

22. Jue, C.K.; Lipke, P.N. Determination of reducing sugars in the nanomole range with tetrazolium blue. J. Biochem. Biophys. Methods 1985, 11, 109-115. [CrossRef]

23. Calderón-Cortés, N.; Watanabe, H.; Cano-Camacho, H.; Zavala-Páramo, G.; Quesada, M. cDNA cloning, homology modelling and evolutionary insights into novel endogenous cellulases of the borer beetle Oncideres albomarginata chamela (Cerambycidae). Insect. Mol. Biol. 2010, 19, 323-336. [CrossRef]

24. EMBOSS Merger. Available online: http://www.bioinformatics.nl/cgi-bin/emboss/merger (accessed on 16 October 2020).

25. Altschul, S.F.; Gish, W.; Miller, W.; Myers, E.W.; Lipman, D.J. Basic local alignment search tool. J. Mol. Biol. 1990, 215, 403-410. [CrossRef]

26. Magoč, T.; Salzberg, S.L. FLASH: Fast length adjustment of short reads to improve genome assemblies. Bioinform 2011, 27, 2957-2963. [CrossRef] [PubMed]

27. Bolyen, E.; Rideout, J.R.; Dillon, M.R.; Bokulich, N.A.; Abnet, C.C.; Al-Ghalith, G.A.; Alexander, H.; Alm, E.J.; Arumugam, M.; Asnicar, F.; et al. Reproducible, interactive, scalable and extensible microbiome data science using QIIME 2. Nat. Biotechnol. 2019, 37, 852-857. [CrossRef]

28. Quast, C.; Pruesse, E.; Yilmaz, P.; Gerken, J.; Schweer, T.; Yarza, P.; Peplies, J.; Glöckner, F.O. The SILVA ribosomal RNA gene database project: Improved data processing and web-based tools. Nucleic Acids Res. 2012, 41, D590-D596. [CrossRef]

29. Yilmaz, P.; Parfrey, L.W.; Yarza, P.; Gerken, J.; Pruesse, E.; Quast, C.; Schweer, T.; Peplies, J.; Ludwig, W.; Glöckner, F.O. The SILVA and "all-species living tree project (LTP)" taxonomic frameworks. Nucleic Acids Res. 2014, 42, D643-D648. [CrossRef] 
30. Ceja-Navarro, J.A.; Karaoz, U.; Bill, M.; Hao, Z.; White, R.A., 3rd; Arellano, A.; Ramanculova, L.; Filley, T.R.; Berry, T.D.; Conrad, M.E.; et al. Gut anatomical properties and microbial functional assembly promote lignocellulose deconstruction and colony subsistence of a wood-feeding beetle. Nat. Microbiol. 2019, 4, 864-875. [CrossRef]

31. Xu, L.; Lu, M.; Xu, D.; Chen, L.; Sun, J. Sexual variation of bacterial microbiota of Dendroctonus valens guts and frass in relation to verbenone production. J. Insect Physiol. 2016, 95, 110-117. [CrossRef]

32. Xu, L.; Deng, J.; Zhou, F.; Cheng, C.; Zhang, L.; Zhang, J.; Lu, M. Gut microbiota in an invasive bark beetle infected by a pathogenic fungus accelerates beetle mortality. J. Pest Sci. 2019, 92, 343-351. [CrossRef]

33. Montagna, M.; Gómez-Zurita, J.; Giorgi, A.; Epis, S.; Lozzia, G.; Bandi, C. Metamicrobiomics in herbivore beetles of the genus Cryptocephalus (Chrysomelidae): Toward the understanding of ecological determinants in insect symbiosis. Insect Sci. 2015, 22, 340-352. [CrossRef]

34. Shukla, S.P.; Vogel, H.; Heckel, D.G.; Vilcinskas, A.; Kaltenpoth, M. Burying beetles regulate the microbiome of carcasses and use it to transmit a core microbiota to their offspring. Mol. Ecol. 2018, 27, 1980-1991. [CrossRef] [PubMed]

35. Franzini, P.Z.N.; Ramond, J.-B.; Scholtz, C.H.; Sole, C.L.; Ronca, S.; Cowan, D.A. The Gut Microbiomes of Two Pachysoma MacLeay Desert Dung Beetle Species (Coleoptera: Scarabaeidae: Scarabaeinae) Feeding on Different Diets. PLoS ONE 2016, 11, e0161118. [CrossRef]

36. Rasko, D.A.; Altherr, M.R.; Han, C.S.; Ravel, J. Genomics of the Bacillus cereus group of organisms. FEMS Microbiol. Rev. 2005, 29, 303-329. [CrossRef] [PubMed]

37. Huang, S.; Sheng, P.; Zhang, H. Isolation and identification of cellulolytic bacteria from the gut of Holotrichia parallela larvae (Coleoptera: Scarabaeidae). Int. J. Mol. Sci. 2012, 13, 2563-2577. [CrossRef] [PubMed]

38. Mereghetti, V.; Chouaia, B.; Montagna, M. New Insights into the Microbiota of Moth Pests. Int. J. Mol. Sci. 2017, 18, 2450. [CrossRef] [PubMed]

39. Jensen, G.; Hansen, B.; Eilenberg, J.; Mahillon, J. The hidden lifestyles of Bacillus cereus and relatives. Environ. Micobiol. 2003, 5, 631-640. [CrossRef] [PubMed]

40. Wang, Y.; Zhang, Y. Investigation of Gut-Associated Bacteria in Tenebrio molitor (Coleoptera: Tenebrionidae) Larvae Using Culture-Dependent and DGGE Methods. Ann. Entomol. Soc. Am. 2015, 108, 941-949. [CrossRef]

41. Römling, U. Cellulose biosynthesis in Enterobacteriaceae. In Cellulose: Molecular and Structural Biology; Brown, R.M., Jr., Saxena, I.M., Eds.; Springer: Dordrecht, The Netherlands, 2007; pp. 107-122. [CrossRef]

42. Boonmak, C.; Limtong, S.; Jindamorakot, S.; Am-In, S.; Yongmanitchai, W.; Suzuki, K.-i.; Nakase, T.; Kawasaki, H. Candida xylanilytica sp. nov., a xylan-degrading yeast species isolated from Thailand. Int. J. Syst. Evol. Micobiol. 2011, 61, 1230-1234. [CrossRef]

43. Cadete, R.M.; Lopes, M.R.; Rosa, C.A. Yeasts Associated with Decomposing Plant Material and Rotting Wood. In Yeasts in Natural Ecosystems: Diversity; Buzzini, P., Lachance, M.-A., Yurkov, A., Eds.; Springer International Publishing: Cham, Switzerland, 2017; pp. 265-292. [CrossRef]

44. Berry, C. The bacterium, Lysinibacillus sphaericus, as an insect pathogen. J. Invertebr. Path 2012, 109, 1-10. [CrossRef]

45. Hammer, T.J.; Janzen, D.H.; Hallwachs, W.; Jaffe, S.P.; Fierer, N. Caterpillars lack a resident gut microbiome. PNAS 2017, 114, 9641-9646. [CrossRef]

46. Watanabe, H.; Tokuda, G. Cellulolytic systems in insects. Ann. Rev. Entomol. 2010, 55, 609-632. [CrossRef] [PubMed]

47. Kliot, A.; Kontsedalov, S.; Lebedev, G.; Brumin, M.; Cathrin, P.B.; Marubayashi, J.M.; Skaljac, M.; Belausov, E.; Czosnek, H.; Ghanim, M. Fluorescence in situ Hybridizations (FISH) for the Localization of Viruses and Endosymbiotic Bacteria in Plant and Insect Tissues. JoVE 2014, 84, e51030. [CrossRef] [PubMed]

Publisher's Note: MDPI stays neutral with regard to jurisdictional claims in published maps and institutional affiliations. 